\title{
Identification of rhabdoviral sequences in oropharyngeal swabs from German and Danish bats
}

\author{
Melina Fischer ${ }^{1}$, Conrad M Freuling², Thomas Müller², Juliane Schatz², Thomas Bruun Rasmussen³ ${ }^{3}$ Mariann Chriel',
} Anne Balkema-Buschmann ${ }^{5}$, Martin Beer ${ }^{1}$ and Bernd Hoffmann ${ }^{1 *}$

\begin{abstract}
Background: In the frame of active lyssavirus surveillance in bats, oropharyngeal swabs from German ( $N=2297)$ and Danish ( $N=134)$ insectivorous bats were investigated using a newly developed generic pan-lyssavirus real-time reverse transcriptase PCR (RT-qPCR).

Findings: In total, 15 RT-qPCR positive swabs were detected. Remarkably, sequencing of positive samples did not confirm the presence of bat associated lyssaviruses but revealed nine distinct novel rhabdovirus-related sequences.

Conclusions: Several novel rhabdovirus-related sequences were detected both in German and Danish insectivorous bats. The results also prove that the novel generic pan-lyssavirus RT-qPCR offers a very broad detection range that allows the collection of further valuable data concerning the broad and complex diversity within the family Rhabdoviridae.
\end{abstract}

Keywords: Pan-lyssavirus PCR, Rhabdoviridae, Dimarhabdovirus supergroup

\section{Findings}

In the frame of active lyssavirus surveillance in bats [1], oropharyngeal swabs from 2297 German bats (sampled during May 2010 and September 2013) and 134 Danish bats (sampled during August to September 2013) were investigated, using a novel generic pan-lyssavirus real-time reverse transcriptase PCR (RT-qPCR) [2]. While all of those were previously tested negative by specific real-time RT-PCRs for the detection of European bat lyssavirus type 1 and 2 as well as Bokeloh bat lyssavirus, in total, 15 swabs from bats originating from the Northeast of Germany (12) and Central Jutland in Denmark (3) had Cq values between 33.5 and 44.6 when using the assay targeting a conserved region on the polymerase (L) gene [2].

Sequencing of those amplicons revealed nine distinct rhabdovirus-related sequences (GenBank accession numbers: KJ614421 - KJ614427, KJ873057, KJ873058) outside of the lyssavirus genus. The remaining six

\footnotetext{
* Correspondence: Bernd.Hoffmann@fli.bund.de

${ }^{1}$ Institute of Diagnostic Virology, Friedrich-Loeffler-Institut, Südufer 10, D-17493 Greifswald-Insel Riems, Germany

Full list of author information is available at the end of the article
}

amplicons were identical to one of the nine sequences. Nucleotide BLAST [3] analysis showed nucleotide identities ranging from $75-86 \%$ compared to previously described members of the Rhabdoviridae family within the dimarhabdovirus supergroup (dipteran-mammal associated rhabdovirus [4]).

The partial L gene sequences from virus samples 26907 [KJ614425, Myotis nattereri], 27676 [KJ614426, Eptesicus serotinus] and RV-DK2 [KJ873058, Myotis daubentonii] however, showed the highest homology with less than 80\% with Isfahan virus [AJ810084], Kotonkan virus [HM474855] and Long island tick rhabdovirus [KJ396935]. These rhabdoviruses were isolated from the sandfly Phlebotomus papatasi, from Culicoides sp. and from Amblyomma americanum, respectively. The sequences of the German samples 26530 [KJ614421, Myotis nattereri], 26855 [KJ614422, Myotis mystacinus], 26873 [KJ614423, Eptesicus nilssonii], 26876 [KJ614424, Eptesicus nilsonii] and 29130 [KJ614427, Myotis bechsteinii] as well as the Danish sample RV-DK1 [KJ873057, Myotis daubentonii] showed the highest identities with 


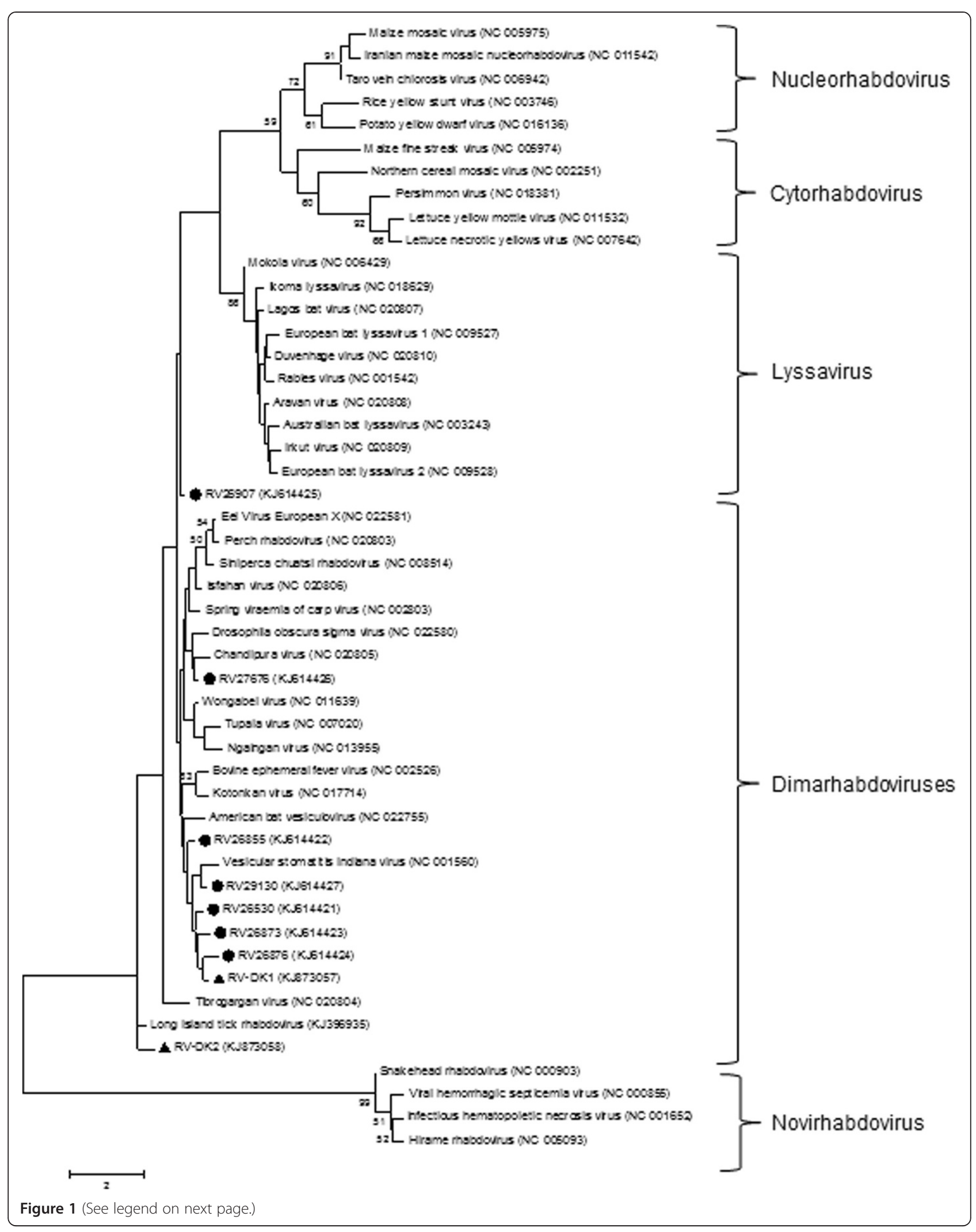


(See figure on previous page.)

Figure 1 Phylogenetic analysis of novel rhabdovirus-related sequences obtained from active surveillance of German ( ) and Danish bats $(\boldsymbol{\Delta})$. The evolutionary history was inferred by using the Maximum Likelihood method based on the Kimura 2-parameter model [5]. For the phylogenetic analysis the RefSeq sequence information for Rhabdoviridae available in GenBank and the Long Island tick rhabdovirus were used. Bootstrap values higher than 50\% were depicted. The tree with the highest log likelihood $(-4926,7333)$ is shown. The percentage of trees in which the associated taxa clustered together is shown next to the branches. Initial tree(s) for the heuristic search were obtained automatically by applying Neighbor-Joining and BioNJ algorithms to a matrix of pairwise distances estimated using the Maximum Composite Likelihood (MCL) approach, and then selecting the topology with superior log likelihood value. A discrete Gamma distribution was used to model evolutionary rate differences among sites ( 5 categories $(+G$, parameter $=0,4501)$ ). The tree is drawn to scale, with branch lengths measured in the number of substitutions per site. The analysis involved 49 nucleotide sequences. All positions containing gaps and missing data were eliminated. There were a total of 143 positions in the final dataset. Evolutionary analyses were conducted in MEGA6 [6].

less than $75 \%$ for different strains of Wongabel virus, Mossuril virus or Bovine ephemeral fever virus.

A preliminary phylogenetic analysis using RefSeq sequence information from the family Rhabdoviridae in GenBank confirmed the affinity of all nine distinct rhabdovirus-related sequences among the dimarhabdovirus supergroup (Figure 1). The differences between the BLAST search and the phylogenetic relationship is based on the fact, that only a limited number of sequence data were integrated in the phylogenetic analysis. Furthermore the BLAST search and the phylogenetic analysis use clearly different algorithms for the identification of sequence similarities and phylogenetic relations, respectively. Nevertheless, the pan-lyssavirus RT-qPCR targets a highly conserved genome region in the polymerase (L) gene and was used as an independent alternative to the frequently used nucleoprotein $(\mathrm{N})$ gene targeting assays. The fragment size of $172 \mathrm{bp}$ is very short and suboptimal for conclusive sequence analyses. Thus the generation of further sequence information, including whole genome sequencing would be valuable for further phylogenetic analyses of these samples. However, the available sample material and the viral genome load were very limited.

For the German samples, based on the generated sequence data, specific real-time RT-PCRs were developed and applied (Table 1), using the OneStep RT-PCR Kit (Qiagen, Hilden, Germany). Briefly, $5.5 \mu$ l RNase-free water, $2.5 \mu \mathrm{l} 5 \mathrm{x}$ OneStep RT-PCR Buffer, $0.5 \mu \mathrm{l}$ OneStep RT-PCR Enzyme Mix, $0.5 \mu \mathrm{dNTP}$ Mix (10 mM each), $0.5 \mu \mathrm{l}$ ResoLight Dye (Roche, Mannheim, Germany), $0.25 \mu \mathrm{l}$ of each primer $(20 \mathrm{pmol} / \mu \mathrm{l})$ and $2.5 \mu \mathrm{l}$ RNA template or RNase free water for the no template control (NTC) were used for each reaction. The following thermal program was applied: 1 cycle of $50^{\circ} \mathrm{C}$ for $30 \mathrm{~min}$ and $95^{\circ} \mathrm{C}$ for $15 \mathrm{~min}$, followed by 45 cycles of $94^{\circ} \mathrm{C}$ for $30 \mathrm{~s}, 56^{\circ} \mathrm{C}$ for $30 \mathrm{~s}$, and $72^{\circ} \mathrm{C}$ for $30 \mathrm{~s}$. Subsequently melt curve analysis was performed $\left(1 \mathrm{~min} 95^{\circ} \mathrm{C}, 1 \mathrm{~min} 55^{\circ} \mathrm{C}\right.$, increase $0.5^{\circ} \mathrm{C}$ per cycle for $10 \mathrm{~s} ; 55-95^{\circ} \mathrm{C}$ ). Obtained viral genome loads ranged between quantification cycle $\left(\mathrm{C}_{\mathrm{q}}\right.$ ) values of 26-36 (Table 1) indicating medium to low viral loads.

Recently, highly sensitive sophisticated molecular techniques have been used to elucidate the role bats play in

Table 1 Oligonucleotides used for specific PCR systems and resulting $\mathbf{C}_{\mathbf{q}}$-values for rhabdoviral sequences of German bats

\begin{tabular}{|c|c|c|c|c|c|}
\hline Assay & Primer & Position (nt)* & Sequence $\left(5^{\prime}-3^{\prime}\right)$ in the L-gene & $\mathrm{C}_{\mathrm{q}^{-} \text {value }}$ & Reference \\
\hline \multirow[t]{2}{*}{ Rhabdo 1} & rhabdo-L1-F & $6-139$ & GAGAGTATTITGTTGTAACTGAGC & 28.5 & KJ614426 \\
\hline & rhabdo-L1-R & & GTCTAGACCTTGTCCATTGGA & & \\
\hline \multirow[t]{2}{*}{ Rhabdo2 } & rhabdo-L2-F & $3-128$ & TGAGGGAGTATTTCGTGATGAC & 30.3 & KJ614425 \\
\hline & rhabdo-L2-R & & GTCCGCTTGATGTTTCCAGC & & \\
\hline \multirow[t]{2}{*}{ Rhabdo3 } & rhabdo-L3-F & $4-147$ & GAGAGACTACTTTGTCATCACTG & 28.6 & KJ614422 \\
\hline & rhabdo-L3-R & & TCGTAATCATCTAGACCTTGTCC & & \\
\hline \multirow[t]{2}{*}{ Rhabdo4 } & rhabdo-L4-F & $4-123$ & GAGGGATTACTITGTAATAACTGAG & 31.8 & KJ614427 \\
\hline & rhabdo-L4-R & & AGCCTTGGCCATTTGATGTATTC & & \\
\hline \multirow[t]{2}{*}{ Rhabdo5 } & rhabdo-L5-F & $3-147$ & TTCGCGACTACTTCGTCATAAC & 25.9 & KJ614424 \\
\hline & rhabdo-L5-R & & TCGTAATTGTTTAATCCCTGTCC & & \\
\hline \multirow[t]{2}{*}{ Rhabdo6 } & rhabdo-L6-F & $1-134$ & GCTGAGGGATTACTTTGTAATTAC & 34.6 & KJ614421 \\
\hline & rhabdo-L6-R & & ATCCTTGTCCATTTGACGTGTC & & \\
\hline \multirow[t]{2}{*}{ Rhabdo7 } & rhabdo-L7-F & $1-140$ & GTTACGAGATTACTTTGTGATCAC & 35.8 & KJ614423 \\
\hline & rhabdo-L7-R & & TGTCCAGGCCTTGTCCATTG & & \\
\hline
\end{tabular}

*Position according to reference. 
the epidemiology of rhabdoviruses. Our results corroborate previous studies that have revealed the presence of novel rhabdoviruses or rhabdoviral sequences in bats from Africa, America and Europe [7-13]. Similar to a previous study which detected rhabdoviral RNA in oropharyngeal swabs from Spanish bats using a generic nested RT-PCR [13], we were not able to decipher whether the viral sequences originated directly from the infected bats or from their arthropod/insect prey animals, because all positive samples were collected from different insectivorous bats. However, the fact that the majority of viruses with the highest sequence homology are rhabdoviruses of insects, suggests an arthropod origin for these novel sequences.

In conclusion, we were able to detect novel rhabdovirus-related sequences in oropharyngeal swabs obtained from German and Danish bats, using a generic pan-lyssavirus L-gene RT-qPCR. As indicated previously [2], this system offers an extremely broad detection range. Moreover, the PCR-assay allowed the collection of valuable data to increase our knowledge of the broad and complex diversity within the family Rhabdoviridae.

\section{Abbreviations}

$\mathrm{C}_{\mathrm{q}}$-value: Quantification cycle value; dimarhabdovirus: Dipteran-mammal associated rhabdovirus; L-gene: Polymerase gene; RT-qPCR: Real-time reverse transcriptase PCR.

\section{Competing interests}

The authors declare that they have no competing interests.

\begin{abstract}
Authors' contributions
$M F$ and TBR performed the laboratory experiments and analyzed the data. MF, TBR, MC, CMF, TM, ABB, MB, and BH conceived of the study, participated in its design and coordination and helped to draft the manuscript. JS collected the German swab samples and extracted the nucleic acid. MC coordinated the collection of samples from Denmark. BH performed the phylogenetic analysis. MF, TBR, CMF, TM, JS, ABB, MB, and BH contributed to final the manuscript preparation. All authors read and approved the final manuscript.
\end{abstract}

\section{Acknowledgments}

We thank Jeannette Kliemt and Helle Rasmussen for excellent technical assistance and Hans J. Baagøe and Esben Fjederholt for collection of the swab samples from Danish bats. This study was supported by the BMBF grant 01KI1016A "Lyssaviruses - a potential re-emerging public health threat", the Research and Policy for Infectious Disease Dynamics program (RAPIDD) of the Science and Technology Directorate, Department of Homeland Security, USA, and by an intramural collaborative research grant. For the latter, the initiative and support by Thomas C. Mettenleiter is gratefully acknowledged. The sampling in Denmark was supported by the Danish Veterinary and Food Administration.

\section{Author details}

${ }^{1}$ Institute of Diagnostic Virology, Friedrich-Loeffler-Institut, Südufer 10, D-17493 Greifswald-Insel Riems, Germany. ${ }^{2}$ Institute of Molecular Virology and Cell Biology, Friedrich-Loeffler-Institut, Südufer 10, D-17493 Greifswald-Insel Riems, Germany. ${ }^{3}$ DTU Vet, Technical University of Denmark, Lindholm, DK-4771 Kalvehave, Denmark. ${ }^{4}$ DTU Vet, Technical University of Denmark, DK-1870 Frederiksberg C, Denmark. ${ }^{5}$ Institute of Novel and Emerging Infectious Diseases, Friedrich-Loeffler-Institut, Südufer 10, D-17493 Greifswald-Insel Riems, Germany.
Received: 8 September 2014 Accepted: 29 October 2014

Published online: 25 November 2014

\section{References}

1. Schatz J, Ohlendorf B, Busse P, Pelz G, Dolch D, Teubner J, Encarnação JA, Mühle RU, Fischer M, Hoffmann B, Kwasnitschka L, Balkema-Buschmann A, Mettenleiter TC, Müller T, Freuling CM: Twenty years of active bat rabies surveillance in Germany: a detailed analysis and future perspectives. Epidemiol Infect 2013. doi:10.1017/S0950268813002185.

2. Fischer M, Freuling CM, Müller T, Wegelt A, Kooi EA, Rasmussen TB, Voller K, Marston DA, Fooks AR, Beer M, Hoffmann B: Molecular double-check strategy for the identification and characterization of European lyssaviruses. J Virol Methods 2014. http://dx.doi.org/10.1016/j. jviromet.2014.03.014.

3. NCBI Nucleotide BLAST [http://www.ncbi.n/m.nih.gov/BLAST/Blast.cgi? PROGRAM=blastn\&PAGE_TYPE=BlastSearch\&LINK_LOC=blasthome]

4. Bourhy H, Cowley JA, Larrous F, Holmes EC, Walker PJ: Phylogenetic relationships among rhabdoviruses inferred using the $L$ polymerase gene. J Gen Virol 2005, 86(Pt 10):2849-2858. doi:10.1099/vir. 0.81128-0.

5. Nei M, Kumar S: Molecular Evolution and Phylogenetics. New York: Oxford University Press; 2000.

6. Tamura K, Stecher G, Peterson D, Filipski A, Kumar S: MEGA6: molecular evolutionary genetics analysis version 6.0. Mol Biol Evol 2013, 30:2725-2729. doi:10.1093/molbev/mst197.

7. Conrardy C, Tao Y, Kuzmin IV, Niezgoda M, Agwanda B, Breiman RF, Anderson LJ, Rupprecht CE, Tong S: Molecular Detection of Adenoviruses, Rhabdoviruses, and Paramyxoviruses in Bats from Kenya. Am J Trop Med Hyg 2014 May 27. doi:10.4269/ajtmh.13-0664.

8. Ng TF, Driscoll C, Carlos MP, Prioleau A, Schmieder R, Dwivedi B, Wong J, Cha Y, Head S, Breitbart M, Delwart E: Distinct lineage of vesiculovirus from big brown bats, United States. Emerg Infect Dis 2013, 19:1978-1980. doi:10.3201/eid1912.121506.

9. Ghedin E, Rogers MB, Widen SG, Guzman H, da Rosa AP T, Wood TG, Fitch A, Popov V, Holmes EC, Walker PJ, Vasilakis N, Tesh RB: Kolente virus, a rhabdovirus species isolated from ticks and bats in the Republic of Guinea. J Gen Virol 2013, 94(Pt 12):2609-2615. doi:10.1099/vir.0.055939-0. Epub 2013 Sep 23.

10. Kading RC, Gilbert AT, Mossel EC, Crabtree MB, Kuzmin IV, Niezgoda M, Agwanda B, Markotter W, Weil MR, Montgomery JM, Rupprecht CE, Miller BR: Isolation and molecular characterization of Fikirini rhabdovirus, a novel virus from a Kenyan bat. J Gen Virol 2013, 94(Pt 11):2393-2398. doi:10.1099/vir.0.053983-0. Epub 2013 Aug 12.

11. Aréchiga Ceballos N, Vázquez Morón S, Berciano JM, Nicolás O, Aznar López C, Juste J, Rodríguez Nevado C, Aguilar Setién A, Echevarría JE: Novel lyssavirus in bat, Spain. Emerg Infect Dis 2013, 19(5):793-795. doi:10.3201/ eid1905.121071.

12. Vazquez-Moron S, Juste J, Ibanez C, Aznar C, Ruiz-Villamor E, Echevarria JE: Asymptomatic rhabdovirus infection in meridional serotine bats (Eptesicus isabellinus) from Spain. Dev Biol 2008, 131:311-316.

13. Aznar-Lopez C, Vazquez-Moron S, Marston DA, Juste J, Ibáñez C, Berciano JM, Salsamendi E, Aihartza J, Banyard AC, McElhinney L, Fooks AR, Echevarria $\mathrm{J}$ : Detection of rhabdovirus viral RNA in oropharyngeal swabs and ectoparasites of Spanish bats. J Gen Virol 2013, 94(Pt 1):69-75. doi:10.1099/ vir. 0.046490-0.

\section{doi:10.1186/s12985-014-0196-x}

Cite this article as: Fischer et al:: Identification of rhabdoviral sequences in oropharyngeal swabs from German and Danish bats. Virology Journal 2014 11:196. 